\title{
Trabajos de alumnos
}

\section{"Un sueño algo especial..." \\ Marcela Rius*}

\section{Resumen:}

El principal objetivo de este trabajo es el análisis y la observación de una niña de dos años. La Psicología Evolutiva se encarga de estudiar este desarrollo (ontogenia).

J. PIAGET explica el desarrollo a través de estadios, procesos continuos con estructuras que por algún desequilibrio tienden a equilibrarse permitiéndo pasar a un estadio superior.

H. WALLON cita la importancia de este período para la formación del individuo, coincidiendo con un proceso dado también por estadios, pero siendo éstos discontinuos, con crisis y saltos apreciables.

S. FREUD desde la teoría psicoanalítica, explica los procesos primario y secundario para comprender así la formación de las instancias que componen nuestro aparato psíquico.

J.BOLWBY incorporará términos como apego y conducta de apego para ejemplificar los comportamientos en la primera infancia.

La integración de todos estos enfoques permite tener una visión totalizadora del niño en este período.

Palabras clave: Estadio - proceso - crisis - aparato psíquico - apego - ontogenia desarrollo - Psicología Evolutiva.

\section{Abstract:}

\section{"Some special dream..."}

The main objective of this paper is the aanalysis and observation of a two-year-old girl.

Developmental Psychology is the discipline that studies this development (ontogeny).

J.PIAGET explains development though stages, continuous structured process of equilibration, passing on to a higher stage.

* Alumna de la Carrera de Psicología en la Universidad de Palermo. Trabajo realizado en la cátedra Psicología Evolutiva I a cargo de la Profesora Alicia Oiberman : mrius@palermo.edu.ar. Av.Pedro Goyena $7292^{\circ}$ "A". Buenos Aires - Argentina. 
Psicodebate. Psicología, Cultura y Sociedad

H. WALLON stresses the importance of this period in the development of the individual and mentions a process which also takes place through stages, but in this case discontinuous ones with crises and significant gaps.

S. FREUD adopts the psychoanalytic approach to explain the primary and secondary processes in order to understand the components of our psyche.

J. BOWLBY incorporates terms such as attachment and attachment bonds to explain forms of behaviour during early childhood.

The integration of all these approaches enables us toreach a global view of the children during this stage.

Key words: Stage - process - crises - psyche - attachment - ontogeny - development Development Psychology. 


\title{
Introducción:
}

No me resultó nada sencillo comenzar esta monografía . Fue muy rico para mí poder hacer esta observación y pensar como organizar el trabajo. Durante los días que me llevó hacerlo escribí algo que quise plasmarlo aquí, tiene mucho que ver con el tema, no tiene título, pero como durante el trabajo se desarrollarán conceptos y teorías me gustaría ponerle : "DESDE EL CORAZON":

\author{
Un día te pense \\ E intenté imaginarte \\ Como serías hija mía? \\ Fue mi pregunta incesante. \\ Muy pronto te conocí, \\ Y tu luz inundó mi vida \\ De dicha y felicidad. \\ Tus primeros pasos quedaron \\ Marcados en mi alma, \\ Tu sonrisas y tus palabras \\ Es algo innimaginable. \\ Te amo por encima de mí, \\ Por sobre el sol de la mañana, \\ Te sueño y vuelvo a pensarte, \\ Pero se que estás ahí, \\ Por el resto de mi vida."
}

Comencemos, ahora, en términos generales como se define la psicología;" es el estudio científico de la conducta, incluyendo procesos conductuales que no son observables como gestos, discursos, cambios fisiológicos y los procesos que solo pueden inferirse como pensamiento y sueños ( Crack y Miller, 1970; v. en Gross, 1998) y de manera mucho mas reciente, se define como el estudio científico de la conducta de los individuos y de los procesos mentales (Zimbardo 1992; v. en Gross 1998).

Así como fueron evolucionando las definiciones del término, sus especificaciones y enfoques, paralelamente el individuo también siguió un camino evolutivo o desarrollo llamado ontogenia, desde su inicio hasta el estado adulto. La Psicología Evolutiva, es la especialidad de esta ciencia que estudia el desarrollo del hombre.

El principal objetivo de mi trabajo es el análisis y la observación de una niña de dos años, para lo cual sería muy importante comenzar explicando que el desarrollo infantil sólo se dará si existen estructuras anatómicas y una determinada organización fisiológica que viene dada con el nacimiento, una disposición del 
cuerpo y viseras, sistema endócrino y el sistema nervioso que asegure el elemental funcionamiento biológico, aunque sabemos que no es suficiente.

A través del estudio del sistema nervioso central se consigue elaborar criterios para establecer una edad madurativa. El nivel de ésta nos muestra lo posible de una actividad y el funcionamiento de las estructuras pre-formadas en la línea general del desarrollo; pero el desarrollo sabemos que no es un proceso unitario y continuo, tanto su unidad y continuidad se ven afectados por diversos factores biológicos, ecológicos, de entorno, la adaptación a un ambiente específico, la relación con la madre, por lo que la dotación de base será distinta en cada uno de los individuos y por lo tanto su eventual desarrollo hasta la madurez.

La imagen del bebé fue cambiando a lo largo de la historia, cada pueblo y cultura le asignó un valor diferente a la infancia y de acuerdo a esto las posturas y/ o tendencias para su estudio fueron diversas.

Por encontrarme en los comienzos de la Licenciatura en Psicología, esbocé los conceptos fundamentales de diversos autores, poder hacer un trabajo exhaustivo y detallado de cada una de sus teorías, demandará algunos años más pero intentaré con mis conocimientos aproximarme a las mismas.

Para ello lo mejor será utilizar un poco de nuestra imaginación.

Para ello utilizaré de Sigmund Freud "El sueño". El lo define como un fenómeno psíquico cuya fuerza impulsora es un deseo por cumplir (en este caso realizar una observación a una niña de 2 años, Victoria, y que cada uno de los autores elegidos participen de la misma , como si estuviesen en una "junta", mientras Yo la relato).

En el anexo se encuentra la foto de nuestra principal protagonista y una de sus primeras obras de arte.

Antes de comenzar a soñar daré las características más importantes del marco en que se realizó dicha información.

Victoria nació el 28.04 .98 mide alrededor de $98 \mathrm{~cm}$. Su tez es blanca, ojos marrones bastante grandes, pómulos rosados, pelo castaño oscuro ondulado hasta la altura de los hombros, su boca es pequeña de un color rosa más oscura, su piel es suave y sus bracitos extendidos llegaban alrededor de la mitad de sus muslos. Tenía puesto un vestido a cuadros con medias y zapatos de color azul. Vive con su madre en un departamento luminoso de la Capital Federal y concurre todos los días entre las dos y las cinco de la tarde a una guardería a unas cuadras de su casa. El contexto donde se realizó es el living de su casa, que linda con el consultorio de la madre. Fue alrededor del mediodía por lo que estabamos iluminados por la luz natural.

Quienes participaran de mi sueño serán: JEAN PIAGET, SIGMUND FREUD, HENRI WALLON Y J. BOWLBY.

El trabajo de interpretación del mismo queda por cuenta de la persona que lea este trabajo, aunque lo conveniente es una interpretación fraccionada, pero no olviden que puede haber objeciones y asociaciones múltiples que no tienen esclarecimiento ya que operan como resistencia para llegar al acceso de mi Inconciente. 


\section{Desarrollo:}

...Toco el timbre del departamento y Victoria abre la puerta de entrada tomando la manija de la misma con una mano, teniendo que estirar su cuerpo en su máxima extensión poniéndose en puntas de pie, es decir apoyando solamente la parte anterior de sus piecitos para lograr abrirme, en la otra mano sostenía un recipiente con cereales el cual había agarrado presionando el borde del mismo con todos los deditos desde su parte superior como si fuesen garras.

Luego de abrirme, escuchó que la madre me ofrecía un sillón para que Yo pudiera sentarme, cuando intenté levantarme al cabo de unos minutos ella volvió a señalarme el sillón acompañado por HI! HI!.

Ante esta primera parte del relato JEAN PIAGET intervino de la siguiente manera:

- Para intentar describir la evolución de la niña sobre el concepto de equilibrio, el desarrollo mental es una construcción continua que a cada estructura se le añade otra que la hace más sólida y superior a la anterior, el análisis de las mismas marca las diferencias u oposiciones de un nivel a otro de la conducta, por eso, existen períodos de desarrollo.

Victoria se encuentra en el final del período sensorio-motor y en la etapa inicial del período preoperatorio. El sistema de esquemas de asimilación sensorio-motrices desembocan en una especie de lógica de acción que implica poner en relaciones y correspondencias (funciones) ajustes de esquema en una palabra. Es el elemento clave para explicar el desarrollo cognitivo, su universo práctico está formado por objetos permanentes e indican el inicio de un proceso de descentralización.

En el final del sexto estadio de la constitución de inteligencia sensoriomotora, la coordinación de los esquemas se independiza lo suficiente de la percepción inmediata y de la experiencia empírica como para dar lugar a combinaciones mentales. Dicho de otra manera el titubeo se interioriza y la coordiación tiene lugar antes de dar lugar a un ajuste exterior.

Aparece a esa edad una función fundamental como vértice entre el final de un período y el inicio del otro: la Función Semiótica o Simbólica, que consiste en representar un significado (objeto, acontecimiento, etc.,) por medio de un significante diferenciado que solo sirve para esa representación." (Piaget, 1972).

Entre los presentes se encontraba HENRI WALLON que acotó:

- Si bien Yo sostengo que la evolución es gradual y la de estadios funcionales, de etapa en etapa, la psicogénesis de la infancia muestra, a través de la complejidad de los factores y de las funciones, a través de la diversidad y oposición de las crisis que la puntualizan una especie de unidad solidaria, tanto dentro de cada una de ellas como en su conjunto. Iríamos en contra de la naturaleza si tratáramos a Victoria fragmentariamente. Cada edad 
Psicodebate. Psicología, Cultura y Sociedad

constituye un conjunto indisoluble en la sucesión de sus edades es un ser único e idéntico." (Carretero y Palacios, 1984).

- Victoria se encuentra en el Estadio Sensorio Motor, está casi totalmente vuelta hacia el exterior, responde a las impresiones que las cosas ejercen sobre ella por gestos dirigidos hacia ella, pude modificar la acción y provocar nuevas.

Freud con sus teoría psicoanalítica no quiso quedar afuera, podríamos decir de esta imaginaria y pequeña "junta":

- Pese a que lo que he observado hasta el momento no me muestran indicios de la etapa o del desarrollo sexual de la niña quiero aportar en términos generales lo siguiente: El neonato trae consigo gérmenes de emociones sexuales que siguen desarrollándose durante cierto lapso, y ya en el acto de ingerir alimento goza también de una satisfacción sexual que después busca crearse, una y otra vez, en la bien conocida actividad del chupeteo. Pero después sufren una progresiva sofocación, ésta a su vez puede ser quebrada por oleadas regulares de avance del desarrollo sexual suspendido por peculiaridades individuales. Las excitaciones provenientes de todas estas fuentes no se conjugan todavía, sino que persiguen por separado su meta, que no es otra que la ganancia de cierto placer, como dije antes. Por lo que infiero que en la niñez la pulsión sexual no está centrada y al principio carece de objeto, vale decir es autoerótica. El florecimiento de la vida sexual de la niña ha de situarse a partir de los tres años por consiguiente Victoria se encuentra dentro de la organización pregenital, más precisamente en la fase anal La zona corporal más sensible y placentera es, ahora, la cavidad anal, los músculos del esfínter de la parte baja del intestino y los músculos del sistema urinario. La preocupación principal reside en expulsar y retener la heces, la etapa se divide en dos subetapas, la primera de expulsión y la segunda de retención. En la primera se observará que la niña experimentará su primer encuentro con las restricciones externas sobre su deseo de defecar cuando y donde le place en el momento en que la madre lo entrene para ir al baño. Este es un momento crucial para la niña ya que aprende a ganarse la alabanza y la aprobación, el amor de su madre ya no es incondicional sino que ahora depende del modo en el que el niño se comporta. En la segunda sub-etapa se puede derivar placer sensual de la retención liberada de "aferrarse a" las heces, por primera vez considera a su madre en este caso, como autoridad." (Freud, 1997).

Debo continuar entonces con mi relato... La madre se agachó en posición de cuclillas para limpiarle la nariz con un pañuelo. Ella (Vicky), también optó por esa posición mientras su madre continuaba con la acción. En ese momento ésta se sienta en el suelo del living donde nos encontrábamos, en posición de "indio", es decir, con ambas piernas flexionadas y superpuestas, ella imita esta posición pero 
en lugar de flexionar las piernas las estira y sólo flexiona apenas unos centímetros una de ellas, para lograr tocarse con la mano correspondiente al mismo lado de la pierna la punta del zapato, extendiendo su brazo y sus dedos, luego alza la cabeza y me mira. Esto dura aproximadamente unos segundo, comienza a moverse hacia otro sector no muy alejado de donde estaba empujándose para ello con la cola hasta lograr alcanzar un muñeco que ahí tenía. Toma el muñeco, siempre con el recipiente aferrado a una de sus manos. Intenta levantarse, deja primero el muñeco y luego el recipiente y apoya una mano en el piso, luego hace lo mismo con la otra, ambas palmas bien abiertas, sus dedos extendidos y algo separados unos de otros, se apoya en ambas y de un solo intento levanta la cola con lo cual queda su cabeza un tanto inclinada hacia abajo y ella en posición de "carretilla", endereza luego el torso superior y sale corriendo hacia su habitación...

JEAN PIAGET vuelve a intervenir:

- "Es importante comprobar que la imitación no constituye nunca una conducta que satisfaga a sí misma, resulta siempre de una acomodación especial al modelo propuesto, pero que suscita esta acomodación imitativa en la medida en que dicho modelo es asimilado de cerca o de lejos a un esquema propio o análogo. Por lo que digo que la imitación es siempre una prolongación de la inteligencia., pero en el sentido de una diferenciación en función modelos nuevos. Al nivel en que se encuentra Victoria la imitación con su madre resulta interesante, la niña imita a menudo sin saberlo, por simple confusión de la actividad del otro con la suya propia. Si quieren aceptar todos los presentes la definición propuesta es egocentrismo infantil, un fenómeno de confusión del punto de vista con el otro o de la acción de las cosas y las personas con la actividad propia. Siguiendo con la imitación representativa de este nivel, por oposición a la imitación sensorio-motora, es la que aparece la representación imaginada del modelo, y precede su copia, pues estamos hablando de la imitación diferida. La solución a la cual hemos llegado hasta aquí, consiste en considerar la imitación como un simple prolongamiento de las acomodaciones características de la inteligencia sensorio-motora y la imagen mental naciente como una imitación interiorizada.

La imitación sensorio-motora que coordina durante los dos primeros años las percepciones y los movimientos hasta desembocar en la construcción del objeto permanente, del espacio práctico y de las constancias perceptivas de la forma y de las dimensiones, conserva un papel fundamental durante el desarrollo mental y hasta en el adulto mismo.

Victoria no imita modelos visuales, sino en la medida en que los comprende. Desde este punto de vista en particular, se podría demostrar que los niveles de imitación son correlativos a los esquemas del objeto y de la causalidad. En tanto que la noción de objeto no se halla constituido, la imitación reposa sobre una especie de indiferenciación entre el modelo y el cuerpo propio y se acompaña de una "causalidad por imitación" 
Contrariamente con la constitución de la noción de objeto y la objetivación de la causalidad, los cuerpos de otros se convierten en una realidad comparable, sin ser idéntica, al cuerpo propio y de ahí proviene este sorprendente esfuerzo de correspondencia entre los órganos percibidos sobre el modelo y los órganos propios, el cual desemboca en la representación de éste. Como dije ya anteriormente la imitación depende de la inteligencia a cada instante, pero no se confunde con ella, pues la inteligencia tiende a un equilibrio permanente entre la asimilación y la acomodación, mientras que, la imitación prolonga la acomodación como tal, de la cual constituye el positivo y le subordina consecuentemente a la asimilación.

Con respecto al espacio, la evolución de éste es enteramente solidaria de la construcción de los objetos. Al principio hay tantos espacios no coordinados entre sí como campos sensoriales (espacios bucal, visual, táctil, etc) y cada uno de ellos está centrado en los movimientos y actividad propios. El espacio visual por ejemplo, no conoce al principio las mismas profundidades que la niña habrá de construir al final de los dos años, en el cual el espacio es general y comprende a todos los demás que caracteriza las relaciones de los objetos entre sí ."

HENRI WALLON lo interrumpe aduciendo lo siguiente:

La maduración progresiva de los centros nerviosos, a esta edad, ha conectado entre sí los diferentes campos sensoriales y motores de la corteza cerebral. Por lo tanto las exploraciones de la mano pueden dar todos los resultados, pero no son suficientes. No exceden el espacio cercano, el que tiene por radio la longitud del brazo. La actividad sensorio-motriz, que es la dominante de este estadio debe ser prolongada por otras dos: la marcha y la palabra. Solo los desplazamientos activos de la niña le permitirán integrar en el mismo espacio continuo sus ámbitos sucesivos. Solo el poder reducir personalmente la distancia le hará sensible el lugar relativo de los objetos a los que se acerca o de los que se aleja. El descubrimiento de este espacio locomotor empieza por hacerle experimentar esa especie de enajenación que expresan sus carreras de un lugar a otro, de una a otra habitación. Pero al mismo tiempo, identifica de manera más completa los objetos que descubre o que encuentra a su voluntad.

Proseguiré a continuación mi relato:

...Me trae una cartuchera cerrada que me dá extendiendo su brazo y dice "ABI", yo lo hago y dentro de ésta hay algunos crayones de colores, lápices y también dos tizas. Toma uno de los crayones entre sus dedos índice y pulgar mientras que los dedos restantes quedan semicerrados, en ese instante toma otro de la misma forma pero con la otra mano y se sienta nuevamente en el suelo de la siguiente manera: se pone en posición de cuclillas y deja caer la cola de golpe, su cuerpo se inclinó primero hacia un costado por el impacto un tanto brusco y luego se estabilizó quedando sentada en un ángulo de 90 grados con ambas piernas estiradas y abiertas. En el centro de éstas puso un cuaderno que tenía cerca de ahí, que tomó con ambas manos utilizando, de un lado del mismo solo el pulgar y del otro lado del cuaderno los cuatro deditos restantes. Comenzó a realizar "trazos". 
Su atención se pierde al cabo de unos minutos, la madre interviene, entonces y le dice:

- Victoria, trae tu pizarrón. Ella se levanta de la misma forma que antes y corre a buscarlo a su habitación, por las dimensiones del mismo, obviamente algo más grande que ella, lo trae arrastrándo, hasta que su madre le dice:

- Vicky lenvantálo que al piso le duele. Entonces la niña arquea un poco su cuerpo hacia atrás y con un poco de esfuerzo logra traerlo hasta donde estamos nosotros elevándolo unos centímetros del piso y lo apoya contra la pared.

Toma una tiza y comienza a realizar trazos sobre éste. Busca otra tiza con la mano que tenía libre y con ambas comienza a realiza trazos simultáneamente, siendo éstos menos visibles que los anteriores.

- Otras de las conductas que podemos observar aquí dice JEAN PIAGET es el dibujo del cual presenta el mismos placer funcional y el mismo autotelismo que el juego simbólico, y la imagen mental con la que comparte el esfuerzo de la imitación de lo real.

Luquet lo considera como un juego pero resulta que aún en sus forma iniciales no asimila cualquier cosa, no importa cuál, sino permanece como la imagen mental, más próxima a la acomodación imitadora. Victoria se encuentra en la fase de realismo fortuito, la de los garabatos, con significación que se descubre luego.

Aunque la frase fue dicha por la madre entiendo que Victoria al comprenderla y modificar la acción que estaba realizando le dio intención a una cosa en este caso el suelo lo que yo llamo animismo infantil.

Retomando nuevamente mi relato... Abandona ahora la tarea que venía realizando, es decir hacer trazos sobre el pizarrón, cuando en ese preciso instante suena el teléfono, la madre va a atenderlo y por ser un teléfono inalámbrico se aleja hacia otro sector. Victoria, entonces, sale a paso ligero hacia su habitación, vuelve al cabo de unos segundos con su teléfono de juguete tomándolo con una sola mano mientras que con la otra presiona los botones que tiene dicho aparato en su frente con su dedo índice, Produjo un sonido similar al del timbre del teléfono real, entonces se lo coloca con una mano cerca de la oreja de la misma manera que lo estaba haciendo su madre en ese momento, luego lo coloca sobre la base del teléfono real que se encontraba sobre la mesa, vuelve a irse con paso acelerado dando pequeños saltitos pero apoyando la planta del pie en forma total desde el primer momento de esta marcha, Entra la habitación de su madre y vuelve con un portarretrato que tenia una foto de ella con su papá. Yo le pregunto ¿quien es? (señalándo al padre) y me responde: "PAPA FEDEICO" y se señala a ella y dice "MIA", se lleva el portarretrato a su cuarto y lo coloca sobre la mesa de luz junto a las demás fotos. Retorna al living con un libro de cuentos, lo abre agarrando con su dedo mayor, anular y meñique varias hojas juntas y apoyando en la primera el dedo pulgar, me señala entonces un dibujo de un coche y dice "TUTU", "GUAGUA" y señala un perro, "PIPI" y hace lo propio con un pecesito y señala también la 
pecera que se encuentra en un rincón del living, vuelve la mirada al libro y dice "SHOOL" y señala al sol del dibujo, lo cierra y lo lleva nuevamente a su habitación, abre un cajón con las dos manos, agarra para esto las dos manijas del mismo y tira con fuerza hacia atrás para que éste se abra y guarda el libro mientras repite "A GUADAR AGUDAR", con una leve entonación.

Vuelve al living y pide "PAPA" y señala el recipiente que contenía cereales que había dejado sobre la mesa, lo hace estirándo su brazo y su dedo índice hacia el objeto. Luego se agarra de la mesa y se para en una pierna flexionando la otra por encima de la rodilla formando con ambas piernas un "cuatro", con este movimiento tira el recipiente al suelo y todos los cereales quedan desparramados por el piso, intenta agarrarlos uno por uno y ponerlos otra vez en el bols, a los pocos segundos emite un quejido, se fastidia, mira a la madre y dice "AGADAR", flexiona los brazos hacia arriba con furia, los baja golpea las piernas contra el suelo, llorisquea, entonces su madre le dice: VICKY Traé la escoba así lo juntamos, ella va hacia la cocina, busca detrás de la puerta la escoba la trae tomada con ambas manos y se la dá a su madre, enseguida busca otra cosa para hacer.

Cuando me voy le digo: ¿Me abrís la puerta?, lo hace y sale al pallier hasta donde se encuentra el ascensor, intenta estirando al máximo su cuerpo llegar al botón del mismo, su madre la llama, retoma y estrecha ambos brazos alrededor de mi cuello. Me suelta y me dice chau con la mano bien abierta y haciéndola girar de derecha a izquierda junto con el brazo...

Como soy Yo, dijo JEAN PIAGET, el que comienza a hablar siempre, ésta no será pues una excepción: El resultado más claro de la aparición del lenguaje es que permite un intercambio y una comunicación continua con los individuos. Estas relaciones interindividuales sin duda existen desde la imitación .La imitación de los sonidos sigue un camino parecido, y cuando éstos vienen acompañados de acciones se prolongan para llegar a la adquisición del lenguaje propiamente dicho, como éste no ha sido adquirido en forma definitiva las relaciones con los demás se limitan a gestos corporales y exteriores en algunos casos o con una muestra afectiva global sin comunicaciones diferenciadas.

El lenguaje que posee VICTORIA como pudimos observar en estos minutos es espontáneo desde el punto de vista de las relaciones sociales fundamentales.

Con respecto al pensamiento egocéntrico puro se presenta en esa especie de juego llamadojuego simbólico. El juego constituye la forma de actividad inicial, o por lo menos un ejercicio funcional que va a perdurar toda su vida. El juego simbólico es una clase de juego que tiene un pensamiento individual casi puro, de imaginación e imitación, su función consiste en satisfacer al Yo merced a una transformación de lo real en función de sus deseos.

Hay aquí un razonamiento sensorio-motor (coordinación de esquemas en función de una meta) pero con la intervención de una representación que transforma la realidad y que sirve de intermediario para alcanzar esta meta. La niña no se limita a razonar por medio de actos sobre lo que ve y manipula, pero evoca en imágenes 
y palabras, la meta perseguida y los medios que deben emplear. Después y por el hecho que rebasa el campo perceptivo por medio de la representación le es posible deformar la realidad representada según sus deseos lo que caracteriza, como expliqué anteriormente al juego simbólico.

Todas las acciones que venimos observando en el transcurso de este tiempo, cuyas raíces son esquemas sensorio-motores, más las experiencias afectivas y mentales demostradas por la niña son la fuente de la futuras operaciones. La intuición como vimos muy claramente en estos últimos actos que realizó, sin la simple internalización de las percepciones y los movimientos en forma de imágenes representativas y de "experiencias mentales". Estas se transformarán en operaciones, también, a partir del momento que constituyan sistemas de conjuntos que sean a la vez, componibles y reversibles. Es decir, que dos acciones del mismo tipo puedan componer una tercera acción del mismo tipo, que pueda invertirse o ser vuelta del revés, así quedará constituída en operatoria, obviamente mucho más adelante.

HENRI WALLON interrumpe a PIAGET y acota: El lenguaje contribuye a la identificación de los objetos. El nombre permite a la nena separar al objeto del conjunto perceptivo del que forma parte. Durante el período en que se realizan estos progresos del conocimiento VICTORIA alterna diferentes juegos en los que actúa como personaje activo.

SIGMUND FREUD comenzó a relatar lo siguiente:

Al nacer VICTORIA es puro ello, dado que está en contacto con el propio cuerpo más que con el mundo exterior, y no afecta la lógica y la razón, su única meta es reducir la excitación al mínimo se dice que está gobernado por el principio de placer. El principal desarrollo que sucede en el ello es el proceso primario, una manera de pensamiento en la que se produce una imagen del objeto que se necesita para reducir la tensión. Sin embargo el ello es incapaz de distinguir entre la imagen subjetiva dentro de la memoria y el objeto real, eso se lo deja al yo. Este es la parte del ello que se ha modificado por la influencia directa del mundo exterior, por medio de percepciones conscientes. Se desarrolla de modo gradual, es la parte de la niña que posee un pensamiento de proceso secundario, equivalente con los procesos cognoscitivos de atención, memoria, solución de problemas y posibilita distinguir entre deseo y realidad, lo interno de lo externo y se gobierna por el principio de realidad.

Durante el largo período en el que está atravesando VICTORIA vive en dependencia de su madre, pero deja detrás de sí la formación en su yo de una instancia especial en el cual se prolonga la influencia de sus padres, el superyó.

Cada etapa (donde la secuencia se determina en forma madurativa) implica una manera o medio particular de lograr gratificación y el grado y tipo de satisfacción que experimenta la niña en cada momento dependerá del modo en que es tratado por sus padres.

Hubo alguien que se mantuvo callado hasta este momento escuchando y observando cada una de las intervenciones que se venían realizando, J. BOWLBY, quién dijo: 
- Ninguno de ustedes mencionó, en especial, la relación entre VICTORIA y su madre:

La tendencia a establecer lazos emocionales íntimos, en este caso con su madre, a los que recurrió en busca de protección, consuelo u apoyo corresponden al apego. Aunque si bien la alimentación desempeña un papel muy importante en las relaciones, lo que pudimos observar no solo con gestos, miradas u alguna acción fue la conducta de apego, cuya función fue y es la de protección. Gracias a la interacción que ambas mantuvieron desde el nacimiento de la niña, ésta se siente más segura y le permite por ejemplo explorar, aunque por su edad el espacio y tiempo sea limitado. Sentirá entonces la seguridad de que su madre va a colaborar ante una situación dificil para ella.

Esto le permitirá poco a poco establecerse como estructuras cognitivas influyentes a lo largo de su vida y mostrarse así, más sociable y feliz no sólo con sus padres sino, como en este caso vimos con otras persona como lo hizo." (BOLWBY, 1981.)

\section{Conclusiones:}

Sabiendo que el sueño es un deseo por cumplir , cuando éste fracasa en su intento de entramar el deseo con las diversas representaciones lo deja a éste sin velo, desprovisto de cualquier resistencia, lo cual nos lleva a exponernos a lo traumático y despertar....

Luego de haber leído este trabajo dejaré a mi criterio algunas conclusiones a saber que no fueron expuestas anteriormente:

Para HENRI WALLON la infancia tiene un significado propio y un papel fundamental que es el de la formación del hombre, en este proceso se producen momentos críticos del desarrollo donde son más fáciles determinados aprendizajes. Intenta encontrar el origen de la inteligencia y el origen del carácter buscando las interrelaciones entre las diversas funciones que están presentes en el desarrollo. Un estadio para él es un proceso discontinuo con crisis y saltos apreciables.

Para JEAN PIAGET los estadios son procesos continuos cuyas estructuras por algún deseequilibrio tienden a reequilibrarse, mediante el mecanismo de regulación y permitiendo pasar así a un equilibrio mejor o superior.

Para SIGMUND FREUD el pasado se conserva integro en el inconciente, pues la conciencia no posee como tal ninguna memoria y se limita a alumbrar los recuerdosimágenes depositados en las capas subliminales.

Para J. BOWLBY una conducta de apego ésta preprogramada, tiene raices biológicas, lo que explicaría las fuertes emociones asociadas a ella, para desarrollarse siempre que las condiciones que ya fueron mencionadas lo hagan posible y serán la fuente y base de la conducta del adulto.

Yo considero que cada una de las teorías resalta un aspecto del desarrollo del individuo, los enfoques en algunos coinciden, en otros no tanto, lo que considero de un valor incalculable como para que en el futuro, no muy lejano pueda realizarse una teoría integradora, la cual considero un gran desafío... 


\section{Referencias Bibliográfica}

Bowlby, J.(1981) Conferencia $\mathrm{N}^{\circ}$ 7. Una base segura. Buenos Aires: Paidos.

Carretero M. y Palacios J., (1984). Psicologia evolutiva Tomo I. Madrid: Alianza.

Freud, S. (1997). Teorías Sexuales Infantiles, en Tomo VII, Obras Completas. Buenos Aires: Amorrortu Editores.

Gross, R. D. (1998). Psicologia, la ciencia de la mente y la conducta. $2^{\circ}$ Edición. México: El Manual Moderno.

Piaget J., Wallon, H. (1971), La Homologación de los estadios del desarrollo del niño y el adolescente, en Los estadios en la psicologia del niño, $1^{\circ}$ Parte. Buenos Aires: Nueva Visión.

Piaget, J. (1996). La formacion del símbolo en el niño. Buenos Aires: Fondo de Cultura Económica.

Piaget, J., (1972) Psicologia del niño. Madrid: Morata.

Piaget, J., (1998). Seis estudios de psicologia. Buenos Aires: Ariel. 
Psicodebate. Psicología, Cultura y Sociedad 